\title{
Possibilidades Outras de Empinar Orquídeas: Iniciativas Disparadas Mobilizando a História Oral no PIBID-Matemática ${ }^{1}$
}

\section{Other Possibilities of Climbing Orchids: Initiatives Triggered by Mobilizing Oral History in the PIBID-Mathematics}

\author{
Línlya Sachs*a; Mirian Maria Andrade ${ }^{\mathrm{a}}$ \\ auniversidade Tecnológica Federal do Paraná. PR, Brasil. \\ *E-mail: linlyasachs@yahoo.com.br
}

\begin{abstract}
Resumo
Este texto trata sobre atividades de orientação no Programa Institucional de Bolsas de Iniciação à Docência (Pibid), no curso de Licenciatura em Matemática, do câmpus de Cornélio Procópio da Universidade Tecnológica Federal do Paraná (UTFPR). Durante os anos letivos de 2016 e 2017, com a orientação de duas duplas de alunos, iniciamos nossos estudos e aproximações metodológicas com a História Oral neste espaço de formação inicial de professores. A proposta tinha como principal objetivo olhar para o professor supervisor dos alunos na escola básica e buscar compreensões sobre como esse professor de matemática se torna o professor de matemática que é. Para isso, foram disparadas algumas leituras e exercícios de escritas com os alunos bolsistas. Os alunos produziram escritas autobiográficas relatando sobre suas histórias de vida, lançando uma reflexão sobre o caminho que levou cada um deles para o curso de Licenciatura em Matemática e o que era para ser apenas um exercício sobre escritas de histórias de vida, tomou outras proporções. Os bolsistas elaboraram, também, roteiros de entrevistas, realizaram entrevistas com os professores supervisores, transcreveram os áudios e textualizaram as transcrições. Todo este processo foi delineado pelos parâmetros da História Oral, conforme nos foi possível compreender e exercitar. Desse modo, pretendemos apresentar como essas escritas autobiográficas podem preparar e, neste caso, permearam as entrevistas com os professores supervisores realizadas posteriormente, possibilitando uma reflexão sobre a mobilização da História Oral no âmbito do Pibid.
\end{abstract}

Palavras-chave: Formação de Professores· Escritas Autobiográficas· Licenciatura em Matemática· História Oral.

\begin{abstract}
This paper is related to advising activities in Programa Institucional de Bolsas de Iniciação à Docência (Pibid), in the Undergraduate Course of Mathematics of Federal University of Technology - Paraná, Campus of Cornélio Procópio (UTFPR). During the academic years of 2016 and 2017, we began our studies and methodological approaches with Oral History in initial teacher training with four students. The main purpose was to look at the supervising teacher of students in elementary school and to seek insights on how this mathematics teacher becomes a mathematics teacher he is. In order to do it, some reading and writing exercises were done with the students. They produced autobiographical writings, reporting on their life stories, thinking on the path that led each of them to the Undergraduate Course of Mathematics, and what was meant to be just an exercise in writing life stories, took on other proportions. Students also developed interview scripts, conducted interviews with supervising teachers, transcribed the audios, and textualized the transcripts. All this process was outlined by the parameters of Oral History. In this way, we intend to present how these autobiographical writings can prepare and, in this case, permeated the interviews with the supervisors teachers later realized, allowing a reflection on the mobilization of the Oral History in the scope of the Pibid.
\end{abstract}

Keywords: Teacher Training· Autobiographical Writings. Undergraduate Course of Mathematics. Oral History.

\section{Introdução}

Tenho em casa uma orquídea cujo talo florido, tão majestoso quanto arrogante, aponta o teto quase em linha reta, forçado que foi por uma estaca de arame e por pequenos fios que se pensam mimetizados em sua tarefa de empinar a flor. Dois brotos subverteram as possibilidades e surgiram, tímidos, ao lado do vaso. Os talos que estão para desabrochar seguiram os caminhos que puderam seguir, cada um para seu lado, vergados para o chão, em contraste nítido com o talo empinado. Não tomei nas mãos a tarefa de empinar orquídeas, mas percebo que admiro os dois talos novos - os subversivos na forma que o jardineiro queria dar ao vaso - segundo um viés que, aos meus olhos, deixa mais nítidas as cores e mais explícitas as flores. Há estacas de jardineiro, violentas, e há meus olhos que também empinam as orquídeas (Garnica, 2012, p.332).

Com a intencionalidade de pensar em práticas docentes que sigam pelos caminhos que puderem seguir, subvertendo possibilidades, deixando de lado as estacas de jardineiro e tornando mais nítidas as cores e mais explícitas as flores no processo de formação inicial de professores de matemática é que demos início ao trabalho que aqui temos a intenção de compartilhar com a comunidade acadêmica interessada. Este texto, portanto, trata de apresentar iniciativas e traçar algumas reflexões a partir da realização de atividades, que se apresentaram entre algumas das tentativas de desenvolver

1 Este texto é uma versão ampliada e aprofundada do artigo "Exercícios de escrita de história de vida e História Oral na formação inicial de professores de matemática por meio de um trabalho no PIBID” apresentado no XIV Encontro Nacional de História Oral. 
práticas inspiradas na metodologia de História Oral em espaços formais de formação inicial de professores de matemática. De acordo com Silva (2016, p.175): "processos institucionalizados com vistas à formação de professores de Matemática, que habilitam pessoas para o exercício do magistério nessa área, como por exemplo, licenciaturas em Matemática [...]”, podem ser considerados como sendo esses espaços formais de formação inicial. Neste texto, em particular, tomaremos como espaço formal de formação inicial de professores o curso de Licenciatura em Matemática, especificamente um projeto que esteve vinculado a esse curso por alguns anos: $\mathrm{O}$ Programa Institucional de Bolsas de Iniciação à Docência Pibid. É, portanto, de movimentos intencionais de pesquisas e exercícios outros de formação de professores, realizados nas searas do Pibid-Matemática da Universidade Tecnológica Federal do Paraná (UTFPR), câmpus Cornélio Procópio, que temos autoridade para e queremos comunicar.

Inspiradas em Rolkouski (2006, 2008), demos início às nossas atividades de orientação no Pibid, no curso de Licenciatura em Matemática, desta universidade. Nesse curso, o Pibid estruturava- $\mathrm{se}^{2}$ do seguinte modo: os coordenadores do projeto convidavam alguns professores do curso para orientar duplas de bolsistas. Desse modo, apesar de não sermos coordenadoras do projeto, contribuímos com ele por meio da orientação de alguns bolsistas. Ainda, optamos por realizar essas orientações de modo conjunto, constituindo um pequeno grupo, com duas professoras orientadoras e quatro bolsistas ${ }^{3}$.

Durante os anos letivos de 2016 e 2017, realizamos nossos estudos e iniciamos nossa aproximação teórica e metodológica com a História Oral. Mobilizar a História Oral como metodologia no Pibid nos parecia uma proposta desafiadora, considerando, inclusive, o pouco envolvimento das professoras orientadoras com essa metodologia em termos de pesquisa. Desafiadora tornou, então, essa aproximação a essa metodologia, buscando compreensões, inspirações, diálogos e reflexões, para que pudéssemos colocar em andamento a nossa proposta. Muitas leituras foram nossas companheiras, muitos foram nossos interlocutores e disparadores de nossas compreensões e dúvidas. É a partir desse nosso modo de aproximação com a metodologia de História Oral que podemos delinear nosso entendimento sobre e como esse entendimento nos permitiu o desenvolvimento deste trabalho.

A nossa proposta tinha como principal objetivo olhar para o professor supervisor dos alunos na escola da Educação Básica, onde eles realizavam parte da carga horária semanal prevista do Pibid. Então pensamos numa proposta que estivesse mais próxima de nossas intenções teóricas e metodológicas e que pudéssemos, a partir dela, discutir, também, pesquisa no âmbito do Pibid.

Tocava-nos o trabalho de Rolkouski (2006), em que ele se propôs a pesquisar sobre a história de vida de professores de Matemática, olhando para como essa trajetória faz o professor se tornar o professor de matemática que é. E o professor de matemática, supervisor do Pibid, como se torna o professor de matemática que é? Essa inquietação foi o nosso objetivo com a proposta inicial dessa investigação. Antes, porém, de cuidarmos especificamente desse objetivo - digamos geral da nossa proposta, optamos por desenvolver alguns exercícios com os alunos bolsistas.

Para isso, iniciamos, no grupo de orientação, pela leitura do artigo "História de vida de professores de Matemática", de Rolkouski (2008). Mas tocavam-nos, também, os fragmentos de entrevistas e textos escritos a partir deles, expostos no livro "Viver e contar: experiências e práticas de professores de matemática", de Teixeira et al. (2012), em que são apresentadas onze maneiras (textos) de escutar as narrativas de professores de matemática. À leitura e à discussão de alguns desses textos também nos debruçamos junto aos bolsistas. Ainda, habitaram nossos encontros e conversas Santhiago e Magalhães (2015), Silva (2016) e Tizzo e Silva (2016), em quem pudemos buscar apoio teórico, metodológico e, mais que isso, inspiração. Esse movimento inicial de leituras nos lançou a outras leituras e ganhava fôlego e fortaleza a nossa intenção de estabelecer no Pibid um ambiente em que pudéssemos discutir, entre os demais objetivos desse projeto, pesquisa e, sobretudo, nosso interesse maior, discutir pesquisa com a História Oral sendo mobilizada como metodologia.

Em Andrade e Sachs (2018, p.224), relatamos sobre nossas expectativas e interesses em torno dessa e também de outras iniciativas (atividades realizadas, também, em disciplinas regulares na grade curricular) que foram pensadas por nós no curso de Licenciatura em Matemática:

As expectativas tomaram conta de nós, professoras que propuseram as atividades com História Oral no curso de Licenciatura em Matemática. O que esperávamos com isso? Contribuir com a formação do professor - o que mais poderíamos querer? Em um contexto de tanta valorização, por parte dos professores e, consequentemente, dos alunos, da Matemática - qual Matemática? Aquela que será útil para o professor? Não, claro que não! -, a nossa proposta foi no caminho contrário. Queríamos valorizar histórias de vidas (histórias de vidas que se encontram, de algum modo, com a docência), queríamos valorizar os modos de compreensão desses personagens sobre alguns aspectos de nosso interesse, em particular, e queríamos, ainda, que esses futuros professores também fizessem isso, queríamos que eles se lembrassem (ou soubessem) que a profissão do professor não é um trabalho exato, não lida apenas (se é que lida com isso tudo) com números, com proposições, com teoremas, com demonstrações, com cálculos, mas, essencialmente,

2 Usaremos o verbo conjugado no tempo passado, pois este projeto do Pibid, no qual atuamos como orientadoras, trata-se de um edital cujas atividades foram encerradas no início do ano de 2018 e, portanto, um projeto que não está mais em vigor.

3 Por ter havido troca de bolsistas no Pibid nesse período, os quatro bolsistas não foram sempre os mesmos. Houve, no total, oito bolsistas participando desse grupo. 
com gente! Gente que tem vida, que tem história, que tem memória. Vidas de "pequenas grandes pessoas" ou de grandes pequenas pessoas ou, simplesmente, de pessoas - pessoas que importam!

Posto isso, na sequência deste texto, nos debruçaremos sobre as atividades desenvolvidas e as reflexões realizadas a partir delas.

\section{Escritas Autobiográficas}

Consideramos escritas autobiográficas, de acordo com Gomes (2012, p. 120), como sendo "textos que narram vidas, independentemente de um caráter mais ou menos pessoal, íntimo, profissional ou público". A autora aponta, ainda, algumas condições, baseada em Jean Starobinski, para que uma escrita de si possa ser considerada uma escrita autobiográfica:

[...] o autobiógrafo pode escrever uma página ou vários volumes; contaminar a narrativa de sua vida pelos acontecimentos dos quais foi testemunha distante; datar, com precisão, os momentos de sua narração; fazer um exame de consciência no momento em que escreve; escolher diversos estilos particulares, de modo que não há estilo ou forma obrigatórios para a escrita autobiográfica. Contudo, o estilo, realização do indivíduo, só poderá se afirmar diante das condições gerais referidas anteriormente. Assim, o estilo da escrita autobiográfica pode ser definido como a maneira própria segundo a qual cada autobiógrafo satisfaz essas condições (que requerem apenas a narração verídica de uma vida, e deixam ao escritor o cuidado de regrar sua modalidade particular, seu tom, ritmo, extensão etc.) (Gomes, 2012, p. 106-107).

Concordamos com Garnica (2012, p.340), ao apresentar narrativa como sendo:

[...] a experiência estruturada como relato, como um 'contar', como forma de construir sentidos (um sentido para o si-próprio - aquele que narra, narra-se ao mesmo tempo em que narra algo - e um sentido para o que é narrado) a partir de ações cravadas no tempo, usando a descrição sobre algo, alguém ou sobre si próprio (biografia).

Em História Oral, situamos as narrativas autobiográficas de histórias de vida como pesquisas "interessadas em perspectivas vivenciais amplas, num conjunto de experiências de vida relatadas por determinados atores sociais" (Garnica, 2011, p.7). Os atores sociais aqui presentes são licenciandos em Matemática, que, por meio de um exercício de escrita, compõem narrativas de suas próprias histórias de vida, evidenciando como se tornam os licenciandos que são.

Baseamo-nos na pesquisa desenvolvida por Rolkouski (2006, p.169) para:

[...] compreender como um professor de Matemática torna-se 'o' professor que é. Ou seja, compreender como o indivíduo vai se tornando, ao longo de sua vida, através de suas vivências, de sua relação com outros indivíduos, de sua relação com o contexto que o cerca, este professor de
Matemática, com estas ideias, práticas e resistências.

Essas ideias, práticas e resistências desenham os caminhos (ou os descaminhos) traçados pelos bolsistas até chegarem ao curso de Licenciatura e nele permanecerem.

$\mathrm{Na}$ sequência, após a leitura e discussão dos textos inicialmente propostos, com histórias de vida de professores, os alunos produziram um texto e o socializaram no grupo, relatando sobre as suas respectivas histórias de vida, lançando uma reflexão sobre o caminho que levou cada um deles para o curso de Licenciatura em Matemática.

Rolkouski (2008, p.68) apresenta narrativas, chamadas por ele de "leituras de vida", que constrói a partir de quatro entrevistas com professores de matemática. $\mathrm{O}$ tom literário dessas narrativas parece ter contagiado os bolsistas do Pibid, ao construírem suas narrativas autobiográficas. Uma das entrevistas de Rolkouski (2008), por exemplo, foi aproximada de um personagem de "Morte e Vida Severina", de João de Cabral de Melo Neto:

Adaildes Ferreira da Invenção, Ferreira, inventiva, assim como o Ferrageiro de Carmona do poeta João de Cabral de Melo Neto, o mesmo de Morte e Vida Severina que fala de Severino, nordestino assim como Adaildes, mas que ao contrário de nossa depoente retira-se enquanto Adaildes permanece (Rolkouski, 2008, p. 83).

As escritas autobiográficas dos bolsistas, fugindo de apresentações frias e formais, mais recorrentes em atividades acadêmicas do curso, puderam seguir rumos outros muito possivelmente influenciadas pela inventividade do texto lido. Assim, o que era para ser apenas um exercício sobre escritas de histórias de vida, com a intenção de que ficasse mais fácil compreender nossa proposta maior, tomou outras proporções. Deparamo-nos com histórias de vida que nos tocaram e tocaram o grupo, de modo a disparar discussões outras e atividades outras. Como parte de um processo de conhecer como professores de matemática se tornam os professores que são, os bolsistas do Pibid fizeram um exercício de escrever suas próprias histórias de vida, explicitando como se tornam os licenciandos que são. "[...] não há uma trajetória na docência, mas sim trajetória na vida, e nesta, nessa trajetória de vida, há a docência” (Paula \& Auarek, 2012, p.36-37). Essas escritas autobiográficas tocaram os bolsistas do Pibid e foram importantes para os momentos das entrevistas com os professores supervisores realizadas posteriormente, bem como para os momentos de transcrição e textualização dessas entrevistas.

Ao todo, foram produzidas oito narrativas autobiográficas: da Leziane ${ }^{4}$ (Campos \& Sachs, 2016), da Ana Paula (Moreira \& Sachs, 2016), da Carine, da Luciene, do Rafael (Moreira et al., 2017), do Wendell, da Débora e da Jéssica.

Cada uma delas foi escrita a seu modo, sem interferências

4 Os nomes dos alunos aqui citados são verídicos e foram por eles autorizados de serem divulgados no momento das escritas de narrativas autobiográficas, muitas enviadas para publicação em eventos científicos. Essa opção está em consonância com o que se espera de pesquisas que envolvam a fundamentação teórica e metodológica da História Oral. 
das orientadoras, sem regras, pois entendíamos, assim como nos coloca Gomes (2012), que o modo de fazer, escolhido por cada um, também poderia revelar um pouco da sua história de vida, o estilo próprio que cada um escolhe para satisfazer às suas condições, para se mostrar em trajetória de vida rumo a um curso de Licenciatura, sem mesmo se atentar, teoricamente, a isso. Surpreendia a eles que escrever sobre suas histórias de vida pudesse ser relevante para o nosso trabalho e olhos curiosos nos rodeavam.

Mas fomos nós que nos tomamos pela surpresa, talvez, por não sabermos (e nem esperarmos) que os alunos fossem tão criativos e poéticos nas escolhas ou por não sabermos que a nossa proposta de mobilização da História Oral pudesse enriquecer o trabalho e tocar os bolsistas do modo como tocou, tomando caminhos que não participavam das expectativas iniciais do trabalho.

Uma das bolsistas, por exemplo, contou sua história de vida como se alguém contasse (para o leitor) o que conversou com ela, em um banco de espera. Ela é uma personagem, protagonista de um diálogo:

Quero relatar uma história que me contaram, esses dias atrás, em um banco de espera. Uma moça, acho que posso falar o nome dela, já que não me pediu segredo, Leziane, aluna de uma faculdade, ou universidade, não sei bem. [...] Nossa, como demorou aquele doutor, hein! Então, a moça gostava de conversar. [...] Na pré-escola, sua professora se chamava Vera. Gostava muito de brincar com meninos, jogar bola, esconde-esconde e balançar e, sem muitas recordações dessa etapa, passou a listar os colégios em que estudou. Para que isso? Deixei. Ela queria falar. Quem sou eu para não escutar? [...] (Campos \& Sachs, 2016, p. 1-2).

Outra aluna inundou poesia em sua vida - ou em sua história de vida - e narrou como sua trajetória a trouxe para o curso de Licenciatura em Matemática, tendo como base e interlocutor "o Soneto de Fidelidade", do poeta Vinícius de Moraes:

De tudo ao meu amor serei atento. Amor que traz na significância do sobrenome amoreira. Nasci, ou melhor, abrilhantei feito fogueira no mês de junho, na cidade de Assis. Meu nome Ana, pequeno e cheia de graça. Segunda filha de pais paranaenses. Que me educaram e cuidaram. Antes, e com tal zelo, e sempre, e tanto. Minha infância e parte da juventude morei em sítios ou colônias na região de Assis como o Mussi, Guaritá, Santa Terezinha e Industrial. Estas duas últimas eram em uma Usina, a qual havia uma escolinha. Que mesmo em face do maior encanto, poderia passar os dias a puxar cabelos de boneca, mas não: embirrava e seguia a professora Luzia que subia a colônia com as crianças e eu, que nem tinha idade. [...] (Moreira \& Sachs, 2016, p.1).

Outra bolsista optou por fazer sua narrativa como uma escrita de diário, com relatos de tristezas e alegrias e compartilhando sentimentos e histórias muito pessoais com o leitor:

Querido Diário,

Hoje você ganhou uma nova amiga e com você vou compartilhar todos os meus momentos bons ou ruins... Mas, antes, vou contar um pouco de onde tudo começou...

Juntamente com fogos de $12 \mathrm{~h} 00$, no dia 12 de outubro
1996, eu nasci. Era um dia muito especial na cidade de Assis, comemoração ao dia das crianças e à Nossa Senhora de Aparecida - por isso do meu segundo nome. Chamome Luciene Aparecida de Oliveira Campos, venho de uma família humilde, que sempre morou aqui no interior de São Paulo, na cidade de Tarumã. Minha infância não foi muito fácil, meus pais se separaram assim que nasci. Então, minha mãe me criou praticamente sozinha, trabalhando dia e noite muitas vezes, mas isso não impediu que ela sempre me incentivasse na vida. [...] (Moreira et al., 2017, p. 6).

Essas narrativas todas falam de experiências, trazem experiências, dividem experiências, reconstroem experiências (Tizzo, Flugge, \& Silva, 2015). Não sabíamos, porém, que essas experiências viriam à tona, justamente por não ser previsível, por não haver forma de garantir, por depender essencialmente do sujeito que (as) vive e que escolhe contálas.

Como nos fala Larrosa (2014), a narração, assim como o ensaio e a crônica, é uma linguagem da experiência, mas isso nada garante, pois não se trata de um imperativo. Trata-se de "pensar a experiência não a partir da ação e sim a partir da paixão, a partir de uma reflexão do sujeito sobre si mesmo do ponto de vista da paixão" (Larrosa, 2014, p. 41-42) e isso não se faz em obediência a alguma ordem, já que "o sujeito da experiência não é, em primeiro lugar, um sujeito ativo, e sim um sujeito passional, receptivo, aberto, exposto". De algum modo, porém, os bolsistas sentiram-se impelidos a escrever sobre suas experiências. E ao narrar suas experiências pudemos percebê-las, de acordo com Larrosa (2014), que eram linhas que diziam sobre aquilo que os havia tocado, que tinha os acontecido e os transformado em trajetória.

Em comum, vários descaminhos que levaram os bolsistas a se tornarem licenciandos em Matemática.

As circunstâncias, as frustrações, as mudanças de rota, a pontuação não atingida nos vestibulares, as famílias, as finanças fazem parte desses descaminhos. Ana Paula, entre Economia, Psicologia e Moda, escolheu pela Licenciatura em Matemática. A concorrência do vestibular dos dois primeiros não permitiu que eles se tornassem reais para ela; Moda era o que ela queria, mas depender da sorte para sobreviver não parecia uma opção. Carine, entre o sonho - Direito - e a aprovação no vestibular - Administração de Empresas -, procurou por algo que admirasse: a docência. Mas, também, gostar de matemática e estar próxima à universidade foram fatores que a trouxeram ao curso. Entre tantos descaminhos a bolsa conseguida, mas não realizada, a morte e o vestibular, a dengue e a inscrição -, veio a chamada nominal para o ingresso de Luciene no curso. O que era para ser Engenharia Mecânica, na Unioeste, tornou-se Engenharia Mecânica, na UTFPR e, então, transformou-se em Licenciatura em Matemática. O namoro, a ideia de morar em outra cidade, a nota de corte desviaram Rafael de seu propósito inicial.E o que os mantém no curso? A professora com suas experiências na Educação Básica, a Filosofia, a Lógica Matemática, o olhar de satisfação do professor do passado, o PIBID, o semestre finalizado, as dificuldades já vencidas, o câncer curado... são tantos os (des)caminhos! (Moreira et al., 2017, p. 10-11). 


\section{Histórias de Vida dos Professores Supervisores e as Narrativas Autobiográficas}

Por que escutar professores e professoras de Matemática? Por que escutar professores de Matemática que vivem e constroem suas experiências docentes em um espaço e em um tempo determinados - o espaço e o tempo das salas de aula do Ensino Fundamental e Médio? Uma primeira resposta a essa pergunta seria porque somos, também, professores de Matemática (Paula, \& Auarek, 2012, p.33).

Olhar, escutar e ouvir as histórias de vidas dos professores supervisores do Pibid, já colocamos, era nosso foco principal, neste trabalho com os bolsistas. Foco principal que, nos momentos de escritas e socialização das histórias de vida deles, assumiu postura secundária, trazendo à cena essas escritas autobiográficas como protagonistas. No entanto, após as experiências com as narrativas autobiográficas, e permeados por elas, pudemos nos preparar para ouvir os professores supervisores do Pibid. Para Garnica (2012, p. 340 ), “ouvir o outro - princípio fundamental àqueles que trabalham com narrativas - implica a tentativa de compreender experiências e criar estratégias de ação, por exemplo, para futuros professores. Daí a importância de levar aos cursos de Licenciatura o trabalho com narrativas".

Nesse período, de 2016 a 2017, foram três professores supervisores dos bolsistas que fizeram parte do nosso grupo. A pergunta disparadora para a elaboração do roteiro de entrevista foi: como esses professores de matemática, supervisores do Pibid, se tornaram os professores de matemática que são? A partir dela, elaboramos questões que possibilitassem aos professores narrarem sobre suas respectivas trajetórias. $\mathrm{O}$ roteiro iniciava com questões mais de cunho pessoal, dando ao professor a oportunidade de se apresentar; seguindo de questões sobre sua formação na Educação Básica e na Educação Superior (incluindo, neste caso, se houve outra intenção de formação - que não fosse o curso de Licenciatura em Matemática ou Ciências -, início de outra formação ou mesmo outra formação nesse caminho e, ainda, os motivos que os guiaram pela escolha que fizeram). O roteiro também possuía questões que davam ao professor a possibilidade de falar sobre as influências que o levaram a ser professor de Matemática, sobre outras possíveis atuações profissionais para além de ser professor (fossem elas na área da educação ou não), sobre ser professor e a sala de aula e, por fim, sobre o projeto Pibid e a atuação desses licenciandos nas escolas.
Os roteiros foram enviados previamente aos professores colaboradores para que se sentissem mais confortáveis no momento da entrevista, já que, assim, pensamos, não seriam surpreendidos com indagações que eles não gostariam de comunicar ou pudessem se sentir constrangidos.

As questões do roteiro de entrevista, então, se transformaram em fichas-temas. Elas foram confeccionadas em papel cartolina e continham, cada uma, uma palavrachave referente a uma pergunta do roteiro de entrevista. A ideia era que a entrevista acontecesse, sem a necessidade de ler as perguntas. Essas fichas foram colocadas em frente ao colaborador no momento da entrevista. O uso das fichas-temas, inspiradas na pesquisa desenvolvida por Rolkouski (2006), permitiu o não desvio do assunto no decorrer da entrevista e uma menor interferência do entrevistador durante a fala do colaborador. Essa estratégia foi comunicada aos professores entrevistados antes que se iniciasse cada entrevista. Eles compreenderam a proposta e fizeram uso dessas fichas-temas para direcionar suas falas.

Era certo que o trabalho com as escritas autobiográficas tinha tocado todo o grupo, mas, com o continuar das nossas propostas, como percebemos a importância das escritas autobiográficas nesses momentos das entrevistas com os professores?

Inicialmente, percebemos bolsistas mais sensíveis à convivência e ao diálogo com o professor supervisor. Essa que era uma tentativa de preparação para a entrevista com o professor supervisor do Pibid foi muito mais que uma preparação, disparou uma grande contribuição. Roubou a cena! E essa atividade, que tinha como objetivo conhecer a trajetória de como o professor supervisor do Pibid se tornou o professor que é hoje, fez com que, por exemplo, a aluna tivesse "um olhar mais afetuoso sobre as atitudes do professor" e, como ela disse, "foi inesperado lidar com o sentimento fluindo no olhar do entrevistado".

As entrevistas geraram transcrições e, posteriormente, textualizações ${ }^{5}$. Dois professores concordaram com todo o processo envolvendo a História Oral e o interesse dos bolsistas em saber como eles se tornam os professores que são. Assim, após feitas as textualizações e correções por eles indicadas, foram assinadas as cartas de cessão dos direitos sobre os textos produzidos - parte constituinte dos procedimentos metodológicos da História Oral. Um professor, porém, esteve pouco à vontade durante todo esse movimento. Notamos o desconforto em dar a entrevista, em dizer sobre sua vida.

5 Entendemos transcrição e textualização de acordo com Vianna (2014): "a transcrição é o nome que damos à transformação do registro sonoro em texto "fiel"' (p. 75), trata-se de um procedimento demorado, um exercício atento e exaustivo de transformação do áudio em texto; e a textualização "transforma a entrevista de 'língua falada' em um texto de 'língua escrita', um texto que terá a estrutura, o formato e o grau de elaboração conceitual e técnico que lhe possa ser dado pelo autor" (Vianna, 2014, p. 76), ou seja, trata-se de cuidar do texto transcrito de modo de que ele tenha mais fluência de leitura, sem perder as características ou modificar da fala do colaborador. O momento da textualização permite, por exemplo, modificar a ordem (ou agrupar) em que alguns assuntos foram abordados no decorrer da entrevista. É importante, no entanto, que esse texto não descaracterize a fala do colaborador e que ele possa, após esse procedimento, continuar reconhecendo sua fala agora em forma de texto escrito. É, geralmente, a textualização que é devolvida ao colaborador para que este verifique se deseja acrescentar, manter ou retirar trechos de sua fala, antes que a autorize para uso do pesquisador. A partir da aprovação deste texto, comumente, o colaborador procede com a assinatura da carta de cessão de direitos, cujo cuidado e arquivo ficam por conta do pesquisador. 
Assim, após a realização da transcrição, decidimos não continuar com a textualização. Entendemos que a colaboração deve ocorrer de modo voluntário e, ao percebermos que não era exatamente isso que estava ocorrendo, preferimos descontinuar.

As duas textualizações obtidas, geradas a partir das entrevistas com os professores supervisores do Pibid, Washington e Agnaldo $^{6}$, foram discutidas e analisadas pelos alunos, junto conosco, nas reuniões de orientação. A textualização da entrevista com um desses professores levou à discussão a respeito dos diversos fatores que podem influenciar a formação do professor e de como aspectos da vida pessoal levam o professor a tornar-se o professor que é (Mariano, Cruz, Palkovitz, \& Andrade, 2016).

Washington, nascido em 29 de outubro de 1958, em Cornélio Procópio, Estado do Paraná, o pai era comerciante e a mãe era do lar. Eram dez irmãos, sete homens e três mulheres, Washington foi o penúltimo filho, um dos caçulas da família. [...] Aos 16 anos fez um curso de Aeronáutica, mas diz que pretendia fazer faculdade de Medicina. Na época o seu pai ficou doente após sofrer um derrame e, assim Washington ajudava a família na loja de seu pai no comércio e continuava com os estudos fazendo cursinho em Londrina. Para não ficar gastando com o cursinho decidiu fazer a Faculdade de Ciências Exatas e cuidar da oficina. [...] Formado em 1982, ele ficou 14 anos afastado das atividades docentes trabalhando com sua família no comércio, com peças e acessórios de carros. [...] Em 1995, Washington começou a dar aula através do Processo Seletivo Simplificado (PSS) trabalhando na área de Física, Química, Biologia e Matemática. [...] Em 1996 prestou o concurso regional do Paraná de professor da rede pública, no qual passou para dar aula de Matemática e só em 2004 foi aprovado no mesmo tipo de concurso para dar aula de Física (Mariano et al., 2016, p. 3-4).

Em uma das reuniões de orientação do Pibid, na finalização do primeiro semestre de 2017, uma conversa aconteceu com os quatro bolsistas da época e eles relataram a dificuldade em transcrever emoções. Uma bolsista diz: "na hora que eu ia transcrevendo, eu ia lembrando de tudo, de tudo, da gente sentado assim, de ele naquela emoção, assim... Só que, a hora que você lia, você falava: 'gente! Está nada a ver do que eu senti lá, né, do que ele passou para gente, daquela emoção"”. E a saída que ela encontra para isso é, de alguma forma, inserir a poesia na discussão posterior à textualização, como uma forma de transcrição (refere-se a um procedimento, em História Oral, que permite ao pesquisador a incorporação de elementos externos que não compunham a fala do colaborador na composição da narrativa, como exemplo, o recurso de uma poesia). E essa foi, justamente, a mesma estratégia utilizada por ela em sua narrativa autobiográfica, com referência ao Soneto de Fidelidade. Nisso percebemos mais um modo interessante de as escritas autobiográficas dos alunos terem permeado a textualização das entrevistas dos professores.
Na limitação, a aluna buscou uma saída - uma saída que ela também precisou buscar devido à limitação imposta pela escrita da sua própria história de vida. Mas sabe ela que essa saída não sanou todas as limitações impostas pela escrita.

A mesma limitação é descrita por Matucheski (2016), ao dizer da tristeza que sente por não poder transcrever e textualizar o canto dos pássaros que fizeram parte das entrevistas que realizou:

Antes de encerrar este texto, quero registrar uma tristeza minha: em quase todas as gravações das entrevistas é possível ouvir os pássaros cantando na UFPR Litoral. Esse registro me faz lembrar a paz que sinto quando estou no espaço da UFPR Litoral, e isso - aqueles sons, aquela paz - deixou o processo de transcrição menos penoso e mais lírico, mas trouxe também uma angústia: "O que fazer, nas textualizações, quanto ao canto dos pássaros?... Não consegui uma resposta para isso. Então, registro, aqui, a limitação do papel, a limitação do texto escrito, e a minha limitação como autora destes textos: não consegui registrar o canto dos pássaros; não consegui registrar as lágrimas de um colaborador desta pesquisa; e não consegui registrar o que senti enquanto realizava essas entrevistas (Matucheski, 2016, p.342).

Com o caminhar das textualizações e por conta das reuniões em que o grupo se juntava para tratar delas, uma espécie de comparação entre os caminhos trilhados por cada professor e por cada bolsista, na trajetória de ser professor de matemática e futuro professor de matemática, acabou sendo disparada - uma comparação interessante em que similaridades e singularidades desses caminhos puderam ser destacadas.

Numa tentativa de análise das textualizações, uma das bolsistas encontrou no Diagrama de Venn ${ }^{7}$ um modo de tratar das interseções e das particularidades das trajetórias de vida dos professores. A essa tentativa de análise ela chamou "Diagrama de Quem". Finalizou "unindo caminhos" desses professores, no contexto do Pibid.

Essa possibilidade de conhecer melhor o outro que está próximo a mim, disparada pela proposta de saber como o professor de matemática, supervisor do Pibid, se torna o professor de matemática que é, contribuiu para que os bolsistas cuidassem mais e tivessem maior preocupação com o tratamento dado às textualizações - uma preocupação que se mostrou latente e que resultou num trabalho cuidadoso e respeitoso por parte de alunos de um curso de graduação que nunca antes haviam trabalhado com questões dessa natureza.

A História Oral possibilitou romper fronteiras criadas pelo próprio engessamento dos cursos de Licenciatura, permitindonos conhecer quem são os alunos, suas histórias de vida, suas memórias, suas expectativas, e mesmo para que eles pudessem conhecer outros - professores supervisores do PIBID - com suas histórias de vida, nos percursos de ser professor de Matemática (Andrade, \& Sachs, 2018, p.228-229).

6 Os nomes dos professores supervisores aqui citados também são verídicos e foram por eles autorizados de serem divulgados com a assinatura da carta de cessão das textualizações.

7 Referência a diagramas utilizados, no contexto da matemática, para apresentar características e propriedades relativas a conjuntos, como intersecção, diferença e união. 


\section{Conclusão}

Com o encerramento das ações desse projeto Pibid, as atividades com esse grupo foram encerradas. Há, ainda, outras propostas efetivadas para serem comunicadas e compartilhadas.

As entrevistas com os professores, com a sequência de transcrição e de textualização, foram enriquecedoras para o grupo compreender mais sobre as disposições da História Oral e algumas de suas potencialidades. Em relação às escritas autobiográficas, podemos afirmar que foi uma experiência bastante interessante com esse grupo de licenciandos. Uma experiência porque entendemos que foi algo que nos (bolsistas e professoras) tocou, que nos aconteceu e nos transformou.

Por um lado, fomos tocadas pelas histórias de vida surpreendentes dos bolsistas. Não há - ou não costumamos criar - espaço para conhecer as vidas dos futuros professores, que estamos também formando. Desejos, feridas, filhos, trajetórias, mortes, distâncias, viagens, expectativas... nada disso conhecíamos, mas pudemos conhecer e, então, reconhecer vida no outro, naquele com quem convivemos diariamente, dialogamos em sala de aula, pedimos trabalhos e atividades diversas, orientamos em pesquisas e extensão. Formadoras de professores que indicam, vez ou outra, olhos e ouvidos atentos para seus futuros alunos, mas que deixamos passar escutas atentas quando estamos na posição de professoras.

Por outro lado, os bolsistas foram tocados pelas histórias de vida também surpreendentes dos professores supervisores. Aquele professor, que o bolsista acompanha toda semana na escola, que dá conta dos conteúdos e de estar à frente de uma sala de aula, que tem olhos de licenciandos mirando suas atitudes e suas lições de matemática, que permite aos bolsistas desenvolverem atividades em suas aulas, também tem vida, desejos, frustrações, expectativas, famílias, perdas, escolhas. Algumas coisas passam a fazer mais sentido para os futuros professores e alguma empatia com o outro, com o colega bolsista, com o professor supervisor e - por que não? - com o futuro aluno passa a existir.

Pensar em possibilidades outras na formação de professores de matemática, e não apenas as colocadas como estacas pelo jardineiro, permitiu-nos conhecer novas orquídeas - ou velhas, mas com cores e caminhos ainda desconhecidos.

\section{Referências}

Andrade, M.M., \& Sachs, L. (2018). “Obrigada por ter apresentado a História Oral": propostas desenvolvidas e analisadas em um curso de Licenciatura em Matemática. Bolema, 32(60), 212230.

Campos, L. \& Sachs, L. (2016). Histórias de licenciandos: caminhos e percursos de uma estudante do curso de Licenciatura em Matemática. Anais do Encontro Nacional das Licenciaturas,6. Curitiba.

Garnica, A.V.M. (2011). História oral e história da educação matemática: Considerações sobre um método. Anais do Congresso Ibero-Americano de História da Educação Matemática, Covilhã, Portugal.

Garnica, A.V. (M 2012). Estacas em paisagens móveis: um ensaio a partir da narrativa de três professores de Matemática. In: I.A.C.Teixeira, M.J., Paula, M.L.M. Gomes, \& W.A.A. Aurex. Viver e contar: experiências e práticas de professores de matemática, (pp.331-347). São Paulo: Livraria da Física.

Gomes, M.L.M. (2012). Escrita autobiográfica e história da educação matemática. Bolema, 26(42A), 105-137.

Larrosa, J. (2014). Tremores: escritos sobre experiência. Belo Horizonte: Autêntica.

Mariano, D.C.B., Cruz, J F.S., Palkovitz, W., \& Andrade, M.M. (2016). Histórias de vida importam: como o professor de matemática, supervisor do PIBID, se torna o professor de matemática que é. Anais da Semana Acadêmica da Matemática, Cornélio Procópio, Brasil.

Moreira, A.P., Silva, C.G., Campos, L.A.O., Rospirski, R.G., Sachs, L., \& Andrade, M.M. (2017). (Des)caminhos na formação de professores de matemática. Anais do Encontro Paranaense de Educação Matemática, 14. Cascavel, Brasil.

Paula, M.J. \& Auarek, W.A. (2012). Viver e contar. In: I.A.C., Teixeira, M.J., Paula, M.L.M., Gomes, W.A.A Aurex, WAA. (Org.). Viver e contar: experiências e práticas de professores de matemática, (pp.33-40). São Paulo: Livraria da Física.

Rolkouski, E. (2006). Vida de professores de matemática - (im) possibilidades de leitura. 2006. 288 f. Tese (Doutorado em Educação Matemática) - Universidade Estadual Paulista "Júlio de Mesquita Filho", Instituto de Geociências e Ciências Exatas, Rio Claro.

Rolkouski, E. (2008). Histórias de vida de professores de Matemática. Bolema, 21(30), 68-88.

Santhiago, R., \& Magalhães, V.B. (2015). História oral na sala de aula. Belo Horizonte: Autêntica.

Silva, H. (2016) A história oral como abordagem em espaços formativos formais de professores de Matemática. Histemat, $2,168-184$.

Teixeira, I.A.C. Paula M,J, Gomes M.L.M., \& Aurex, W.A.A. (2012). Viver e contar: Experiências e práticas de professores de matemática. São Paulo: Livraria da Física.

Tizzo, V.S., Flugge, F.G., \& Silva, H. (2015). Práticas possíveis com a história oral na formação inicial de professores (de Matemática). Bolema, 29(53), 887-908.

Tizzo, V.S., \& Silva, H. (2016). A história oral na formação inicial de professores (de Matemática): uma abordagem possível no estudo de política educacional brasileira. Revista NUPEM, 8, 27- 47.

Vianna, C.R. (2014). Sem título. In: A.V.M. Garnica, Cartografias contemporâneas: mapeando a formação de professores de Matemática no Brasil, (pp.67-85). Curitiba: Appris. 